Original paper

Accepted: 26.3.2010

\title{
Actions to reduce the impact of construction products on indoor air: outcomes of the European project HealthyAir
}

Philomena M. Bluyssen ${ }^{1 *}$, Sabine de Richemont ${ }^{1}$, Derrick Crump ${ }^{2}$, François Maupetit ${ }^{3}$, Thomas Witterseh ${ }^{4}$, Petr Gajdos ${ }^{5}$

${ }^{1}$ TNO Built Environment and Geosciences, Delft, The Netherlands

${ }^{2}$ IEH, Cranfield University, Cranfield, UK

${ }^{3}$ CSTB, Saint-Martin d'Hères, France

${ }^{4}$ DTI, Hoje Taastrup, Denmark

${ }^{5}$ National Institute of Public Health, Prague, Czech Republic

Running Head: European Project. HealthyAir

Word count of abstract: 125

Word count of text: 8,917

\section{KEYWORDS}

European project, indoor air quality, construction products, end-users' requirements, built environment, regulations and policies

*Corresponding author: Philomena M. Bluyssen

Contact Address: TNO Built Environment and Geosciences, Van Mourik Broekmanweg 6 NL-2628 XE Delft, The Netherlands.

Email: philo.bluyssen@tno.nl

Tel: +31 152763306

Fax: +31 152763016 


\title{
Actions to reduce the impact of construction products on indoor air: outcomes of the European project HealthyAir
}

\author{
Philomena M. Bluyssen ${ }^{1 *}$, Sabine de Richemont ${ }^{1}$, Derrick Crump ${ }^{2}$, François Maupetit ${ }^{3}$, Thomas \\ Witterseh ${ }^{4}$, Petr Gajdos ${ }^{5}$ \\ ${ }^{1}$ TNO Built Environment and Geosciences, Delft, The Netherlands \\ ${ }^{2}$ IEH Cranfield University, Cranfield, UK \\ ${ }^{3}$ CSTB, Saint-Martin d'Hères, France \\ ${ }^{4}$ DTI, Hoje Taastrup, Denmark \\ ${ }^{5}$ National Institute of Public Health, Prague, Czech Republic
}

\begin{abstract}
The European project - HealthyAir is a network project involving six institutions in Europe on actions and activities that address the effects of construction products on indoor air. Different ways to improve indoor air quality were reviewed, ranging from source control to education of occupants on how to manage the built environment to achieve healthy and acceptable indoor air. Through literature study, organised workshops with scientific experts and building professionals, as well as via interviews with three stakeholder groups: producers of construction products, architects and housing corporations; requirements for information, guidance and actions to improve indoor air quality were identified. These requirements formed the basis of a possible approach to improve indoor air quality: education and awareness, regulations and policies, and further research and development.
\end{abstract}




\section{INTRODUCTION}

The need to address the issues of indoor environment at the EU level is recognised, by the Environment and Health Action Plan of the Commission of the European Communities (CEC) which was launched in 2004 [1], the World Health Organisation (WHO) ministerial declaration [2], and, also the Strategic Research Agenda of the European Construction Technology Platform [3]. In the European community, Indoor environment is considered to be an important determinant of an individual's health, particularly when considering that people spend majority of their life indoors, especially at homes where on average nearly 16 hours per day during the week and 17 hours per day during the weekend. For children and elderly people, these figures are even higher [4].

In the past, the provision of appropriate ventilation was considered to be the sole means of achieving good indoor air quality (IAQ) and it was not until the 1990s, that an additional approach, source control, was considered. Furnishing and construction materials, ventilation system components and activities performed by people indoors, can be important sources of pollution, and therefore a ventilation rate based on carbon dioxide $\left(\mathrm{CO}_{2}\right)$ production by building occupants, is increasingly being recognised as not valid in buildings where $\mathrm{CO}_{2}$ is not the dominant source of pollution [5]. The identification and characterisation of indoor pollution sources and the development of guidelines to control them is on-going [6]. During the last decade, there has been a transition in research with a focus on primary emission source to more of an emphasis on secondary emission phenomena, such as products of ozone initiated indoor chemistry [7, 8] and chemicals and biological particles arising from the growth of micro-organisms on interior surfaces [9, 10, 11].

Regarding IAQ, several initiatives have been undertaken at European level ranging from establishing exposure threshold values of pollutants to labelling of products and even labelling of buildings:

- The development of harmonized test methods for the release or emission of dangerous substances to satisfy the requirements of Essential Requirement No. 3 (ER 3) of the Construction Products Directive (CPD) [6].

- A standardised voluntary approach for the delivery of environmental information on construction products, and to assess the environmental performance of buildings [12].

- Harmonisation of several national labelling schemes for construction and furnishing products [13, $14,15]$.

- REACH (Registration, Evaluation, Authorisation and Restriction of Chemicals) [16].

- Several European funded projects including the recently completed co-ordination action on Indoor air quality and health effects (ENVIE) [17].

It is clear that IAQ is still an important issue despite the various initiatives and projects that have already been undertaken. In recognition of this, the European project HealthyAir was initiated as a 
network project sponsored by the Executive Agency for Health and Consumers (formerly Public Health Executive Agency) under the management of DG Sanco (Directorate General for Health and Consumer Affairs of the European Commission) to identify ways forward to improve IAQ.

\section{METHODOLOGY}

The three-year HealthyAir project started in April 2007 with the following general objective:

To define, initiate and develop activities that will improve indoor air quality and reduce exposure of people to indoor air pollution sources, in particularly, construction products.

Three consecutive steps were taken to fulfil this objective.

- Step 1: A State of the art review of the facts and problems related to IAQ from three points of view: the human, the indoor air of the space and the sources contributing to indoor air pollution; to address the question 'Why is indoor air quality (still) an issue?'

- Step 2: Information exchange in the form of a workshop, interviews and a forum was used as a means to answer the questions: 'Is IAQ recognised as an issue by the key stakeholders concerned with the provision, management and uses of the built environments, such as the architect, product producers, and also the end-user, and if not how can awareness of the issue be raised?' Consideration was given to the knowledge status of the stakeholders on IAQ, the information available to them and its adequacy to meet their needs, as well as the most effective methods of communicating.

- Step 3: A possible approach was defined to address the question, 'What can or should be done to reach the next level?' This includes actions and methods to improve IAQ ranging from education to regulation and research opportunities.

\section{STATE OF THE ART}

The state of the art review was undertaken to identify the current state of knowledge on IAQ. In the review indoor air quality was approached from three points of view [18]:

- The human well-being as the receiver and perceiver of health and comfort

- The indoor air of the space as the carrier

- The sources as emitters and contributors to indoor air pollution.

These are three distinct but inter-related aspects of IAQ. A source (or sources) emits pollutants into the indoor air of a space, directly or indirectly. Those pollutants can react with each other or with pollutants from other sources including outdoor sources, creating new compounds (i.e. indoor air chemistry). Also, pollutants can react with surface materials in the building. A person entering or occupying the indoor space would be exposed to those pollutants present in the air of that space; this can possibly induce a physiological response or a health effect, immediately or sometime after, 
probably influenced by previous and "future" exposures in the same or other spaces [18]. It can therefore be difficult to relate a particular response or health effect to a pollutant or a source of emission. Experiments using laboratory controlled exposures of subjects to specific pollutants focusing on particular responses have been carried out [18] but even then, people's response can vary widely and it can be difficult to relate the results to the multi-pollutant exposures and other environmental stressors that can occur in a building over time.

Currently, the standards and guidelines of IAQ that are in use, mainly address the indoor air and to a lesser extent the sources. These include: WHO air quality guidelines [19], ASHRAE [20], EN15251 [21] and several nationally determined minimum guidelines based on the presence of people only and therefore $\mathrm{CO}_{2}$ concentration. Even though those standards and guidelines are met, the quality of the indoor air, as experienced by the occupants, may often still not be acceptable and can cause health and comfort problems. There seems to be a discrepancy between current standards and wishes and demands of end-users [22]. Minimum ventilation rates based mainly on body odour with $\mathrm{CO}_{2}$ as an indicator and to some extent on primary emissions from some building materials, are not preventing occupants and visitors of a space developing health symptoms (asthma, etc) and/or comfort complaints (e.g. odour, irritation).

From the state of the art review, it was concluded that defining IAQ can be difficult. Considering the status of our knowledge with respect to emission, indoor air and human perception, it is not surprising that there are considerable difficulties with defining effective standards and guidelines for good indoor air quality. it is thus not strange that discussions on how much ventilation is sufficient to prevent noxious odour and spread of disease, that have origins in the beginning of the $19^{\text {th }}$ century [23], are still on-going (see Figure 1).

Some facts and problems underlying the conclusions of the state of the art review are listed below and described elsewhere in more detail [18]:

- The emission behaviour of sources is complex.

- Indoor and source surface chemistry create "new" often unidentified compounds, not (yet) accounted for in current standards and guidelines.

- The material constituents and moisture retention characteristics of a product determine the risk for microbial growth.

- The HVAC systems can be a source of pollution as well, if poorly designed, operated and/or maintained, which is not always acknowledged.

- To truly evaluate an exposure, all routes of exposure (both physiological and psychological) should be taken into account. Individuals will react differently to the same exposure.

- There are diverse techniques available to indicate the IAQ people are being or were exposed to. 
- It is difficult to relate symptoms to IAQ evaluations.

- Some compounds may have adverse effects on their own, while others, seemingly harmless, but can become harmful when they interact with each other or over time.

- Some compounds would behave differently and can cause a health effect when in a mixture than when they exist as individual single compound.

- Problems with IAQ are not only source related, but also building process related.

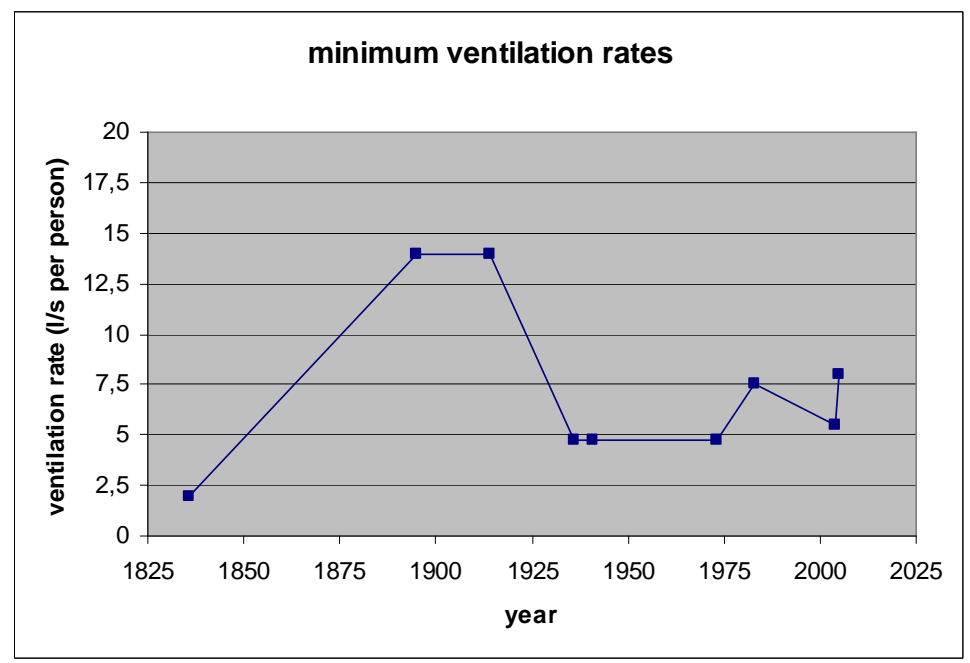

Figure 1. Minimum ventilation rates

The recommended minimum ventilation rate has changed over the years: from 2 1/s per person by Tredgold in 1836, to 14 1/s per person by Billings in 1895 [24], back to 4.7 1/s per person in 1936 by Yaglou to 7.5 1/s per person in 1983 [25, 26]. The current recommended minimum ventilation rate by ASHRAE [20] is $2.5 \mathrm{l} / \mathrm{s}$ per person added with $0.3 \mathrm{l} / \mathrm{s} . \mathrm{m}^{2}$ for single person cellular offices $\left(10 \mathrm{~m}^{2}\right)$ and 4 1/s person added with 0.4 1/s. $\mathrm{m}^{2}$ for single person cellular offices $\left(10 \mathrm{~m}^{2}\right)$ by CEN [21].

\section{INFORMATION EXCHANGE}

Information exchange is a key part of this project. The objectives of the information exchange were:

- To investigate the attitudes of key stakeholders

- To identify actions required

- To raise their awareness about IAQ issues.

In order to facilitate the information exchange with the stakeholders, the project organised a workshop in Rotterdam and interviewed 105 stakeholder organisations. Also a discussion forum was conducted at the Healthy Buildings 2009 international conference which was held on 13-17 September 2009 at Syracuse in New York, USA. The forum was attended by international experts; including practitioners, architects and environmental technologists, as well different sectors of building and material industries. 


\section{Workshop}

The report of the state of the art review provided the themes for a workshop that was held on November 21, 2007 in Rotterdam, Netherlands to have a first discussion on the ways to improve indoor air quality. Thirty people comprising different stakeholders within the building sector (producers of building products, architects, buildings owners, consultants, standardization bodies and research organisation members), attended the meeting. The programme and the summary of the meeting can be found on the website of HealthyAir [www.healthy-air.org].

The issues raised during the discussion are summarised as follows:

- In order to obtain good IAQ in buildings, it is necessary to select low emission products, but also to properly design, operate and maintain ventilation systems. Indoor air quality guidelines, which can be set as objectives to be reached, are also necessary as shown by the experiences demonstrated by initiatives and schemes developed in Finland [39].

- People in charge of building product selection during building design are generally not aware of IAQ issues and do not have smart and simple tools for choosing low emission products. It is therefore necessary to transfer knowledge on IAQ towards people in charge of the design of indoor spaces. This should be done through education of all professionals (e.g. architects) and other stakeholders in the building sector and also through the development of terms of reference, simple tools and criteria, and technical specifications.

- While good IAQ is generally not considered as a priority when designing buildings, the building sector has integrated the global concept of "sustainability" which covers a wide range of issues. Several workshop participants, including building owners, suggested that IAQ should be closely linked to "sustainability" since architects and industry already accept the need for sustainable buildings. This link could have a broader impact than "IAQ only" labels.

- Energy efficient buildings were regarded as a new challenge for the building sector. The drive to increase energy efficiency will probably lead to drastic changes in building design, to more insulation of the envelope and air-tight buildings, to the introduction of new synthetic materials and the reduction of ventilation. Those changes will certainly affect IAQ and therefore source control and ventilation optimisation should no longer be ignored otherwise energy efficient buildings will not be "healthy buildings".

- Several workshop participants expressed their wish for simple actions to be adopted based on current knowledge in order to achieve better IAQ now rather than await the outcome of further research which may recommend other actions at some undefined time in the future. 


\section{Interviews}

Further consultation with different stakeholder groups (architects, producers of construction products and end-users represented by housing corporations) were carried out by interviews undertaken in a number of European countries (The Netherlands, United Kingdom, Denmark, Sweden, France and Czech Republic) as well as at European level (see Table 1). A leaflet providing general information about indoor air quality and the HealthyAir project was circulated before the interview.

Table 1 Interviews per stakeholder group and country.

\begin{tabular}{|l|l|l|l|l|l|l|l|}
\hline Interviews & NL & UK & DK & S & F & CR & total \\
\hline Architects & 5 & 5 & 5 & 1 & 5 & - & 21 \\
\hline National umbrella of architects & 1 & 1 & 1 & 2 & & & 5 \\
\hline ACE & 1 & & & & & & 1 \\
\hline Housing corporations & 5 & 5 & 5 & 5 & 5 & & 25 \\
\hline National umbrella of housing corporations & 1 & & & & & & 1 \\
\hline CECODHAS & 1 & & & & & & 1 \\
\hline Product producers & 5 & 5 & 5 & 8 & 5 & 7 & 35 \\
\hline Product TCs & 5 & & & & & & 5 \\
\hline Umbrella's of industry (incl. FIEQ) & 5 & & 1 & 5 & & & 11 \\
\hline total & 29 & 16 & 17 & 21 & 15 & 7 & 105 \\
\hline
\end{tabular}

The interviews were undertaken to gauge the current knowledge of indoor air quality issues, the information available to stakeholders and the adequacy of this to meet their needs, including those requested by their clients.

During the interviews, the stakeholders were asked about their views on the most effective methods of communicating information and the likely effectiveness of labelling products and/or buildings with respect to IAQ criteria. It also explored current knowledge of interviewees on existing EU and national initiatives on indoor air, and asked about their own policies on sustainable buildings, as well as the main current challenges facing their business sector.

For the analysis, four groups were identified:

- Architects: comprising of the individual architects, the national umbrella's and the Architect's Council for Europe (ACE) which is the European umbrella.

- Housing corporations: comprising of the individual housing corporations, the national umbrella organisations and the European Liaison Committee for Social Housing (CECODHAS) which is the European umbrella.

- Product producers: comprising of individual product manufacturers. 
- The technical committees (TCs) of the various types of construction products within the European Standard Organisation and the umbrellas of industries.

In each participating country, for each of those groups, an analysis was carried out and these were combined into a more general summary applicable to all countries. While the sample was relatively small and therefore not fully representative, the findings are informative (see below).

\section{$\underline{\text { Architects }}$}

In general, the architects and umbrellas of architects interviewed did not consider IAQ to be a priority issue at the moment, except perhaps for schools, although they found IAQ an important parameter in the design process and even more so in the occupational phase of a building. Some architects considered a combination of the competitive market, the clients wish to minimise costs and the client's lack of awareness about IAQ, discouraging. IAQ is almost everywhere linked to ventilation, and therefore keeping to the regulations for ventilation is the current means of dealing with IAQ.

Linking IAQ to health, productivity and energy seems a logical way to show why IAQ is important, but another label whether it is on the product or building level is not immediately embraced. Linking requirements relevant for IAQ to sustainability is probably the best option. Several architects made a plea to involve, make aware and educate the end-user, since they have an important role in determining what is brought into the building and how activities are executed. These end-users can be educated and stimulated via the press (make it a public issue) but also via the internet, booklets and other media. The architects themselves are in need of information and education, because they feel they should know more about IAQ. Some, especially in France, are a step ahead and require emission data for construction products and even a tool with which they can predict IAQ and compare design alternatives. A black list of construction products, rather than a white list, is a wish of some. Measures to improve IAQ, examples of good practice, even a pilot building with good IAQ, are other types of information needed.

There is a need to demonstrate to architects that by the use of appropriate design measures the indoor air quality can be improved. It is very important to show them a diversity of design solutions that achieve good IAQ. If there were examples, it could help them to make their own designs special. General recommendations from the interviews of architects are presented in textbox 1. 
Textbox 1 General recommendations from the interviewed architects

- Information to educate and to increase awareness of architects, end-users and all others involved in the construction sector: There is a clear lack of information on what is needed to improve IAQ. Work should start by making architects and, certainly the end-users and the clients, aware of the importance of IAQ. If one is not aware of what certain measures, products or design options will cause, the problem will never be tackled. Lists of measures, examples of good practice, do's and don'ts, but moreover the basic information required to estimate/evaluate what IAQ is or will be, are needed. The press, internet and personal instructions seemed to be the favoured means to provide the occupant with information, while architects themselves are in need of education, perhaps via the national umbrella of architects.

- Change of design and working practices by including IAQ in the initial design work (briefing) and defining (mandatory or not) performance based requirements: There is a need to change the current way of working, in order that it should relate to improving IAQ, but also needs to be integrated to other evolving topics such as sustainability, energy, health and comfort. The traditional construction process is not functioning optimally, for the afore-mentioned topics. Performance based requirements set at the initiation of a project should form the starting points, and should have the involvement of all stakeholders. The question that arises is of course which performance requirements for IAQ should be taken as a starting point and how these relate to measures and design options. Ventilation requirements are not enough.

\section{$\underline{\text { Housing corporations }}$}

IAQ is in fact IEQ (Indoor Environmental Quality) to the interviewees from housing corporations, and should be linked to energy and comfort. Health should not be influenced negatively by saving energy measures (tighter buildings). If a label is to be applied, it should be linked to energy and regulation measures. Tenants are crucial. According to the majority of the interviewed housing corporations the tenants are mainly responsible for achieving good IAQ and therefore need to be educated. The press particularly television, and also information available on the Internet could help to promote awareness of IEQ issues.

In general, for the housing corporations IAQ is considered important but not a key parameter. For some (e.g. in France), requirements on emissions from construction products are seen as a good way to raise awareness, while at the same time it was pointed out that the link to health and safety outcomes have not been sufficiently clear. A better understanding of the link to health, safety, comfort and productivity would help to make IAQ more of an issue.

Linking to sustainability is in general not preferred, while labelling of products is in general preferred to the labelling of buildings. Information about IAQ and what can be done to improve IAQ for their tenants is wanted because of concern for the comfort of tenants as well as avoidance of possible negative effects on the image of the corporation.

General recommendations from the interviewees of housing corporations are presented in textbox 2 . 
Textbox 2 General recommendations from the interviewees of housing corporations

- Education and awareness of tenants: it is generally proposed to educate mainly the tenant on how to use their buildings. A resident's handbook (supported by one-on-one instruction) is a possibility, but it is also emphasized that the press (national campaigns) and information on the internet can influence the tenant. This influencing should not be based on fear, but a positive angle should be taken. Practical and simple information on how to improve their living situation focusing on their lifestyle (behaviour) is required.

Information needs on IAQ: information related to products in the form of classification and/or labelling, on benefits and examples of good measures. One could learn from an inventory of actual IAQ situations and by checking whether improvements do have the predicted effect.

\section{Product Producers}

According to most of the interviewed product producers, emissions of construction products are not the most important sources that are causing poor IAQ and their own products are definitely not of concern. In general they are of the opinion that their products do not contribute to IAQ problems, including those that do not have emission data. For most of them it is an issue because of the existing labelling systems and for some because it can be a unique selling point (low-emitting healthier products). They see labelling of products as the simplest way because labelling of buildings is complex. But it will only be effective if a product label is mandatory and they would prefer a labelling system at European level. Most of them are aware of the national and international activities and many are involved themselves through trade associations who are active in CEN or the International Standards Organisation (ISO). The general recommendations from the interviewed product producers are presented in textbox 3 .

Textbox 3 General recommendations from the interviewed product producers

- Raise awareness with the general public, but more should focus on how to improve the indoor environment of a building than how to improve the IAQ via the use of construction products. This awareness can be raised by showing the benefits of good IEQ (a clear link with health and comfort) and by examples of good solutions/measures and designs. Again the public should not be made afraid (avoid the fear approach) and it is the task of the authorities and experts to provide appropriate information.

- Mandatory regulations for IAQ, for products or buildings: Some go a step further and are of the opinion that mandatory regulations are the only action that will work. Only then would the product producers themselves take action by testing their own products and developing IAQ friendly products.

\section{Product Technical committees and umbrellas of industry}

In general, the interviewees of the TCs and umbrella's pointed out that IAQ is only one of the safety aspects of a product. Their products either do not contribute to poor IAQ or have only very small effects and there is no benefit in including IAQ awareness in their businesses. Labelling has associated emotional issues. They believe that IAQ will be an important issue in the future. Some argued that the end-users themselves should ask for good products. Both labelling of products and labelling of buildings are identified as the preference. 
An IAQ labelling system should be compulsory and easy to understand in order to promote development of low emitting products. If the labelling has a voluntary status, there will be no demand for it. Regulation seems to be the easiest way to promote IAQ. Linking to sustainability is not supported by everyone. Every way of educating people (information transfer) should be used, but transfer via the press and the media is considered to be the most effective. A 'fear-approach' should not be used. National campaigns could help to educate people. There is a need for classification of products, white lists, examples of good measures, emissions and specialist knowledge from experts. Only some of this is available. The recommendations from the interviewees of the TCs and the umbrella's were more or less the same as those from the product producers (see textbox 3 ).

\section{$\underline{\text { Conclusions from the Interviews }}$}

From the interviews of the three target groups on IAQ and their business related activities, it can be concluded that in general IAQ is not an issue that is actively taken into account. Even though almost all acknowledged the importance of IAQ in relation to health and comfort, most do not have a good technical knowledge as to why it is important. Ventilation is the dominant measure to improve IAQ about which they are aware of, and therefore it is related to the current movement to decrease the use of energy.

Emissions of construction products are not immediately pinpointed as a possible source of poor IAQ. The product producers themselves considered the contribution of their products to be negligible compared to other indoor sources. Only regulation (i.e. labelling of products and/or buildings) and information by authorities could change this point of view.

As long as their clients of all three target groups are not specifically asking for products and buildings that result in good IAQ, they will not take action, unless it is necessary to protect their image. The objective should be an initiative that provides a win-win situation, preferably with a holistic approach that includes all stakeholders involved.

\section{Forum}

The session held at the Healthy Buildings 2009 international conference in Syracuse, New York, attracted around 50 persons from different countries all over the world. The main question discussed was: How to make the end-users aware of IAQ?

There was a common agreement amongst the delegates that education and awareness is an essential action for improving indoor air quality. Probably the best approach would involve education of children at school. They are the future and they will teach their parents. This was seen as appropriate 
for the awareness of energy use, e.g. use of lighting. If children at school learn to turn off the light when they leave a room, they will teach their parents at home. It would be also easier to teach children than their parents from a practical point of view as parents, in general, do not have the sufficient motivation to go to educational classes to learn about IAQ or other issues concerning sustainability. Linking IAQ to sustainability (e.g. reduction of $\mathrm{CO}_{2}$ ) could be an effective approach. In fact it was mentioned by several attendants, that on a small scale some programmes are being trialled for children at school.

At political level (EU), IAQ is being recognized as a public health issue. Therefore, according to some of the attendants, we should also follow the way of standardization at the European or even global level, forcing the stakeholders of the built environment to follow 'the standard rules'. This would require concise information from research, presented to the building community in a 'digestible' way. This opinion was not shared by everyone. Information should not be over-simplified in an attempt to make it easier to understand, because this can make the information 'useless'. This could be symptomatic of us not yet knowing enough to make that transition from information transfer to a 'common knowledge', at a general (i.e. putting things together) or even at a detailed level. Simplicity is different from simple and in many ways clearer for people to develop compliance and understand the standard requirements.

Two opinions could be extracted from the discussion:

- The knowledge is in place but needs to be translated into tools that can effectively reach the intended audience(s) and enable them to put science into action. The interpretation of that knowledge should be interdisciplinary, in order to incorporate results from different sciences and approaches, to give a better and more complete picture of the present knowledge.

- Detailed knowledge and new issues are emerging that need further research and development before these can be communicated to the public. There is also a need for the conclusions to have a much broader application linked to a wider context of building environment.

It was proposed that there is a need to approach education differently and not just translate technical findings into simple terms. The end users (and their activities) should be targeted and therefore the approach to education and awareness activities should take account of their point of view. Bringing together engineers with behavioural experts on this matter could provide a solution. A suitable package of educational material for the different levels of students would be needed.

It was concluded that although different countries have different educational priorities (e.g., school, building managers), a "push \& pull" approach, i.e. regulation and education, will probably be the best way forward. If the IAQ community (i.e. the scientists, engineers, technologists and regulators) are not 
taking action, the stakeholders (e.g. architects, product producers and building owners) who can potentially do something to improve IAQ will not, because their clients are not requiring them to act and ultimately the public will and would not know what to ask for.

\section{POSSIBLE APPROACH}

From the information gathered in the state of the art review, the workshop, the interviews and the forum can be distilled; that the approach required to improve IAQ with a main focus on construction products should comprise of at least three clearly intertwined levels of actions: education and awareness, regulation and policies, and research and development.

\section{Education and awareness}

The general awareness of, "how one can improve IAQ and who should or can undertake action to remediate the situation', is poor, even though most interviewed persons thought that they do have some understanding of the requirements. This awareness can be raised by showing the benefits of good IEQ - by a clear link with health and comfort without causing fear - and by examples of good solutions/measures and designs. According to most parties, this should be the task of the local authorities of governments and experts to provide appropriate information for education of the public and end-users. It is the end-user (client) that would need to be made aware of the IAQ issues, only then will changes occur, that would produce the necessary impact on the other target groups of stakeholders.

In the HealthyAir project, pathways for improving this awareness have been recommended for four stakeholder groups: professionals at university, children at school, practicing architects and tenants (see Table 2).

Table 2 Recommended pathways for improving awareness for four different stakeholder groups.

\begin{tabular}{|l|l|l|}
\hline & Pathway 1 & Pathway 2 \\
\hline Professionals at universities & Undergraduate programme & Specialised courses \\
\hline Practising architects & Workshops and meetings & Umbrella of architects \\
\hline Children at school & Educational programme & Management of school \\
\hline Tenants & Housing corporations & Media \\
\hline
\end{tabular}

\section{Professionals at universities}

Arguably little has changed with regard to the structure of formal education in the indoor air sciences at universities since the study by Boschi and others over 10 years ago [27]. Currently, an ISIAQ (International Society of Indoor Air Quality and Climate) task force aims to review the education requirements in the indoor air sciences and possibly develop tools for selected end users 
[www.isiaq.org]. Also some particular professional training courses have been developed such as described by the Canada Mortgage and Housing Corporation [28] and at international level by NIVA (Nordic Institute for Advanced Training in Occupational Health) [www.niva.org] or courses for HVAC engineers at national level (e.g. by REVHA (Federation of European HVAC Associations) linked organizations). Initiatives, such as the education and symposium activities on IEQ being developed by the International Society of the Built Environment (ISBE) in the UK, China, Hong Kong and Korea would also contribute to the promotion of the issues [www.isbeltd.com].

Educational material is available (for example by Maroni et al. [29] or by Spengler et al. [30], but it doesn't seem to be widely applied in university education, perhaps because the information is too complex, too expensive and/or not appropriate for the particular audience (e.g. limited to a chemical or engineering viewpoint). It is notable that no material has been available, until recently (see [31]), that covers indoor environment quality as a whole and considers different points of views.

In order to assess the amount of training provided to architects, as one of the important groups of professionals; a small survey was undertaken by the HealthyAir project of a sample of UK universities providing education of undergraduate and postgraduate. While the information from UK universities may not be broadly representative it does further support the view that the situation with regard to formal education in the indoor air sciences may not have changed substantially from that reviewed by Boschi [27]. Possibly the most practical method of training architects further about IAQ, at least in the short term, is through an expansion of specialised courses that are recognised for continuing professional development, next to a solid undergraduate programme. The latter should provide clear information about indoor environment quality (including indoor air quality) and the effects on comfort and performances.

\section{Practising Architects}

Based on the interviews described before, it seems that practising architects consider IAQ synonymous with ventilation (room volume) and link to energy performance of buildings. Energy performance has been in general, (there are exceptions of course), a higher priority than selection of IAQ friendly materials for source control, even though the selection of low-emitting products will enable the use of less ventilation and thereby reducing the possible energy requirements of the building.

Environmental aspects and environmental performance of building materials have gained attention during recent years. This is seen in the development of environmental product declarations (EPDs) and several national and international eco-labels, which are used as guides for selection of environmentally friendly products. Although many of the eco-labels are 'cradle-to-grave' or 'cradle-to-cradle' based, 
the focus is typically not on the impact on IAQ in the 'in-use' phase of the product. At national level, some emission testing is in use and labelling schemes have been developed [6]. Unfortunately, most architects are not aware of the existence of those labelling schemes at national level, and are even less aware of the international activities on emission testing or harmonisation of labelling schemes.

Architects should be addressed through workshops and meetings. Workshops held by an expert at individual architectural practices will most probably have the biggest impact, but would also require the most resources in terms of cost and man power, since a large number of individual arrangements have to be made. Additionally, information distributed in written form, e.g. by the architects umbrella organization, in the form of a leaflet, can also be effectively applied.

\section{Children at school}

Children at schools are increasingly the focus of political attention. For example in France, following the Grenelle Environment decisions [32] and the second French environmental health action plan [33],] this attention has grown from a few monitoring projects to the concept of permanent monitoring of IAQ, starting with kindergartens and primary schools. Parallel to the monitoring activities, research is being undertaken with the goal of developing IAQ indices for risk management and in addition attention is being given to improving awareness about IAQ via the Internet.

With these activities an attempt is being made to prescribe how IAQ should be handled for the children and their teachers in schools. The question of how to involve and educate children on this matter and what exactly to teach them, however, remains open. The need to educate children exists, as was identified at the Forum held during the Healthy Buildings 2009 conference in Syracuse. In fact, the majority of the attendants thought this would be the best way to proceed. An educational programme for children, integrated with information on sustainability issues, could begin for children at the age of 7 (once they are able to read) or even younger, e.g. by the use of games.

Initiatives and tools do exist in other countries to help school administrators, facility planners and educators to create a safe and healthy learning environment. For example Health Canada has developed the 'Tools for schools action kit for Canadian schools' [www.hc-sc.gc.ca/ewhsemt/air/in/school-ecole/index-eng.php], which is a practical tool to help schools to understand and address IAQ problems. A custom made information package or handbook for the management of the school comprising of practical and simple information on how to improve the situation focused on the behaviour and activities performed.

\section{Tenants}

The participants of HealthyAir have produced a rough inventory of the type of information channel or medium used to inform tenants, or the general public about how to take care of their own living 
environment in such a way that it is healthy and comfortable. From the participating countries, the Internet was identified as a dominant channel at the moment, television in general is only used when something negative has occurred, for example, carbon monoxide poisoning and exposure to asbestos and fine dust. Information leaflets are available from governmental organisations but these are not actively promoted. However, the information presented often assumes a certain knowledge level of the readers or listeners and, sometimes, can be too technical or is not explained well enough why certain things happened or are required. Although the fear approach is not recommended; realistic information, either positive or negative, would still need to be communicated to the end-users or general public.

The information that can be transferred via the housing corporation can comprise for example; a resident's handbook, including practical and simple information on how to improve their living situation by focusing on their behaviour and lifestyle linked to an existing evaluation system; or by newsletters or domestic TV information channel.

Possibilities to make tenants or the general public, aware via the media include a film, public meetings, newspaper and magazine articles, a leaflet series or perhaps a book (even though many of the interviewees were against this) on how your health can be affected by an unhealthy living environment. For the latter some examples are available at national level (in the Netherlands: [34]; in Germany: [35]; in the UK: [36]). A film or television commercial presentation can influence the public. Examples are public awareness campaigns on ventilation in The Netherlands and in France [http://www.air-interieur.org/oqai,aspx] and the $\mathrm{CO}$ awareness week in the UK to highlight risks of carbon monoxide poisoning [http://www.covictim.org].

\section{Regulations and policies}

With respect to policies, the European project EnVIE [www.envie-iaq.eu] produced a list of recommendations on policies with regard to IAQ linked to the following:

- $\quad$ Energy efficiency, building materials, products and maintenance

- The impacts of the outdoor environment

- Specific building constructions and equipment.

From the regulatory point of view, several ways to control the effects or possible effects on indoor air quality (e.g. exposure to indoor air pollution) are available:

- Minimum allowable emission rates of pollutants from a source (supported by product labelling).

- Ban the use of certain pollutants in products (e.g. asbestos, smoking, certain biocidal products, etc.).

- A minimum required ventilation rate. 
- A maximum allowable concentration level (exposure level), for example for formaldehyde.

- Preventive measures such as design approaches (correct design), maintenance activities to prevent growth of Legionella or strict procedures of intended use of a space or product.

The first two measures focus on the source control, while the third and fourth are dealing with the indoor air management. The last one deals with a combination of sources, indoor air management and human activities.

Regulations on maximum allowable concentrations are valid if a clear relationship has been established between the compound regulated and a health effect. In practice it is difficult to check compliance with these regulations because at present it is not technically and economically feasible to measure pollutants in homes on a regular basis, except perhaps for humidity and elevated levels of carbon monoxide. It is further complicated because the concentration as well as the types of indoor air pollutants may vary widely as a function of both time and space. Also access to homes for measurement would require the permission of the householders and this may not be forthcoming. One possible limited approach is the measurement of IAQ criteria in newly built homes prior to occupation, perhaps in combination with testing of air tightness of the structure [37]. Regulations of products that could possibly emit compounds of concern are potentially an effective approach with benefits to occupants of both new and existing buildings, especially for compounds that are identified as carcinogenic. In fact, when a compound has been clearly identified as being carcinogenic it should be appropriately controlled (e.g. the banning of asbestos and limits provided on the release of formaldehyde from products used indoors).

After the realisation that occupants are not the only polluters in indoor environments [5] and therefore a ventilation rate based on carbon dioxide production of occupants is no longer valid for buildings, and defining the correct ventilation rate has become even more complex. Nevertheless, a minimum ventilation rate to dilute pollutant concentrations should always be required. This minimum ventilation rate should not only be based on the presence of occupants, but should include a certain rate per square meter of surface area of a space [20,21]. Even though materials are selected based on their minimum emission rates, however, some emission will still take place, whether it is primary or secondary emissions. It should be noted that regulating only based on ventilation is not enough! On top of that regulation should require checking of performance, for example, to ensure that the rate of air removed by the installed extract fan or air supplied by HVAC meets the design values [38].

Labelling of products or buildings is a regulatory option including several of the measures presented above. Nevertheless mandatory requirements on emissions from building products are relatively scarce in the EU, most of existing product labelling schemes are voluntary. In the framework of the EU Construction Products Directive, there is an ongoing initiative to establish a harmonised method 
for the characterization of emissions from building products and components by CEN TC 351 and of environmental performance of products and buildings linked to sustainability being developed by CEN TC 350. The question arises as to whether the intended target stakeholder groups will use the labels. If mandatory, the labels will of course have to be used but the system applied must fulfil the purpose for improving indoor air quality. In addition, harmonisation of the most relevant existing voluntary schemes in Denmark, Finland, Germany and France would broaden their individual acceptance and relevance and encourage a greater use of labelled products and the development of new products, which meet the appropriate emissions criteria.

Labelling at the product level, would at least ascertain that the total emissions of products will be reduced and therefore the total amount of substances emitted to the air, will decrease. The Finnish experience with the M1 label has shown that this can work to a certain extent [39]. In the absence of a "complete picture" of the effects of the wide range of substances emitted the pragmatic approach would be to reduce exposure by controlling the sources of emissions.

The building environmental assessment methods such as BREEAM in the UK, LEED in the USA, CASBEE in Japan [www.ibec.or.jp], Green Globes in Canada [www.greenglobes.com], and approaches of ISO [40, 41] and CEN [42] linked to sustainability do not currently include the detailed information that is required to identify the sources of pollutants encountered in the indoor air. These types of schemes provide an assessment of a wide range of sustainability issues but do not guarantee provision of good IAQ. Also they do not provide a process to remediate or replace buildings with poor indoor air quality. Thus although it may be possible for regulators to monitor trends in sustainability issues on a national level it does not guarantee the individual end-user, a healthy building. Any such assessment tool applied at the time of construction and refurbishment would not take account of the influence of occupants' activities in the indoor environment and also changes occurring outdoors such as increased traffic or refurbishment in the vicinity.

Most interviewed parties agreed that some kind of regulation is required to compel action, whether this is at the product level (labelling of products) or at the building level such as the building environmental assessment methods. To link or merge this regulation with sustainability is the most preferred option, which would most likely increase awareness. Finding a way to incorporate the first step for improving IAQ, Source control, should therefore be investigated.

\section{Research and development}

It is clear from the state of the art review that regulations based on IAQ threshold levels are very difficult to formulate because of a lack of knowledge at several levels: the behaviour of the sources, 
the air chemistry and lastly but certainly not least, the human beings that receive or take up the pollutants.

For a long time now, IAQ has been mainly approached from the indoor air point of view by measuring all compounds present and to try to define an appropriate ventilation rate for an indoor situation. Because we know now that starting with the content of the air would not lead to a satisfying solution in the near future, other points of views would also need to be investigated more closely: i.e. the source and the receiver. Currently, a lot of attention is being given to source control and the mechanisms occurring at a particular source and in the air with the evolving knowledge on primary and secondary pollutants. But the fact remains that we still do not have the complete picture to pinpoint which pollutants or mixtures of pollutants, are responsible for which health effects and where those pollutants are originating from. This is partly related to our lack of knowledge on how these health effects may occur and how to measure them in relation to the pollutants over time under different environmental conditions. It is important to acknowledge that:

- Individual differences, emotions, context and time are important parameters.

- Most likely, a multidisciplinary approach is required to improve the understanding of the mechanisms taking place at the source and receiver, and also on "on the way" mechanisms.

- Positive and negative effects of stimuli should be included as well as interactions with other aspects of the indoor environment.

- The human body responds in different ways led by physical, chemical, physiological and psychological processes.

- The current applied indicators are most likely not sufficient to explain the outcome of those processes [43].

Parallel to the research in depth on the mechanisms behind the physical, chemical, physiological and psychological processes, another approach towards IAQ is needed. This requires an increased understanding of how the human body receives, perceives and responds to certain environmental conditions. To study these responses with the human being as the ultimate sensor should be an important direction for the future, taking into account the different exposure routes such as the olfactory neuronal pathway [44], as well as individual differences, context and time.

In addition, we need to reconsider our risk models: to focus on real exposure situations rather than single components, parameters or pollutants in a laboratory (see Figure 2). Multi-exposure effects can only then, be identified. 


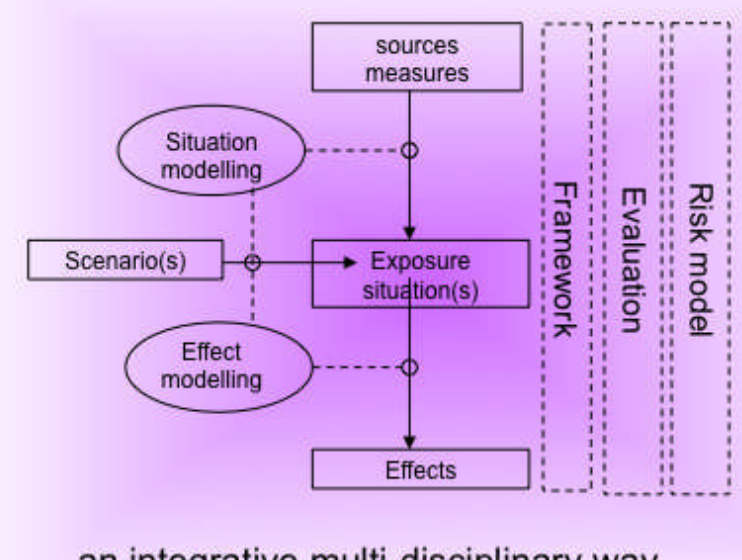

an integrative multi-disciplinary way

Figure 2 Another approach towards IAQ: exposure situations rather than single components?

\section{CONCLUSIONS}

From the various activities undertaken in the HealthyAir project including the state of the art review, the workshop in Rotterdam, the interviews undertaken with the three stakeholder groups and the Healthy Buildings forum, it is clear that in order to improve IAQ, several levels of action will need to be evaluated.

Education and awareness using a "push \& pull" approach is required to make society as a whole, realise the importance of IAQ, ranging from educating school children applying new ways (perhaps a computer based games) to educating building professionals and practising architects with hands-on examples of best practices.

At the same time, regulation and policies for IAQ should be intertwined or at least linked to sustainability and health issues. And lastly but not the least, research and development should focus on multi-exposure situations rather than single compounds and events, using the human being as the ultimate sensor. A multi-disciplinary approach is therefore required to achieve the necessary actions for improving IAQ and for managing future risks to IAQ such as the possible implications of climate change.

\section{ACKNOWLEDGEMENTS}

HealthyAir is partly sponsored by the European Union in the Public Health programme (2003-2008) under the management of Mrs Paloma Martin of the Executive agency for Health and Consumers (EAHC). The coordination of the project was performed by Dr. Philomena M. Bluyssen from TNO Built Environment and Geosciences. Other participants are: CSTB (France), Danish Technology 
Institute (DTI) (Denmark), National Institute of Public Health (Czech Republic), Boverket (Sweden) and Cranfield University (UK).

\section{REFERENCES}

[1] CEC: The European Environment \& Health Action Plan 2004-2010, COM 2004; 416. Final; Volume I: SEC 2004; 729.

[2] WHO: Declaration. Regional Office for Europe; 2004: EU/04/5046267/6.

[3] ECTP: Strategic Research Agenda for the European Construction Sector, Draft version, October 14.

[4] Bonnefoy e $\mathrm{t}$ al.: Review of evidence on housing and health: Proc of Fourth Ministerial Conference on Environment and Health, 23-25 June 2004, Budapest, Hungary: Background document EUR/04/5046267/BD/1.

[5] Bluyssen, P.M., de Oliveira Fernandes, E., Groes, L., Clausen, G.H., Fanger, P.O., Valbjørn, O., Bernhard, C.A., Roulet, C.A.: European Audit project to optimize indoor air quality and energy consumption in office buildings: Indoor Air Journal 1996; 6: 221-238.

[6] EU CEC: Development of horizontal standardised assessment methods for harmonised approaches relating to dangerous substances under the construction products directive (CPD). Emission to indoor air, soil, surface water and ground water. European Commission 2005: M/366.

[7] Weschler, C.J.: Chemical reactions among indoor pollutants: what we've learned in the new millennium: Indoor Air 2004; 14 (Suppl 7): 184-194.

[8] Bornehag, C.G., Sundell, J., Weschler, C.J., Sisgaard, T., Lundgren, B., Hasselgren, M., and Hägerhed-Engmann, L.: The association between asthma and allergic symptoms in children and phtalates in house dust: a nested case-control study: Environ. Health Perspect. 2004; 112: pp.1393-1397.

[9] IUMS: Statements and recommendations from the second international workshop on fungi in indoor environments: towards strategies for living in healthy buildings: International Union of Microbiological Sciences, International Commission on Indoor Fungi, 17-19 March 2005, Utrecht, The Netherlands.

[10] Adan, O.C.G.: On the fungal defacement of interior finishes. Doctoral Thesis, Technical University of Eindhoven, 1994.

[11] Fisk, W.J., Lei-Gomez Q., Mendell M.J.: Meta-analysis of the associations of respiratory health effects with dampness and mold in homes: Indoor Air 2007; vol.17, no.4: pp. 284-296.

[12] EU CEC: European Directive 2002/91/EC 2002 on the energy performance of buildings. Brussels, Belgium, 2002.

[13] CEC: Harmonisation of indoor material emission labelling systems in the EU, Inventory of existing systems: ECA 2005; Report 24: EUR 21891 EN. 
[14] Daumling, C., Brenske, K., Crump, D., Funch, L., Hansen, K., Horn, W., Kephalopoulus, S., Maupetit, F., Saarela, K., Tirkkonen, T. and Witterseh, T.: Harmonisation of material labelling schemes in the EU: Proceedings of Indoor Air 2008, Denmark; paper ID 1074.

[15] Kephalopoulos S., Daumling C., Crump D., Funch L.W., Horn W., Maupetit F., Saarela K., Sateri J., Tirkkonen T. and Witterseh T.: Harmonisation of indoor material emission labelling schemes in the EU: Proceedings of Healthy Buildings 2009; paper 635.

[16] CEC: Regulation (EC) No 1907/2006 of the European Parliament and of the council of 18 December 2006 concerning the Registration, Evaluation, Authorisation and Restriction of Chemicals (REACH). Brussels, Belgium, EU 2006.

[17] Fernandes O, E. de, Jantunen, M., Carrer, P., Seppanen, O., Harrison, P., and Kephalopoulos, S.:EnVIE: Co-ordination Action on Indoor Air Quality and Health Effects. Project no. SSPE-CT2004-502671. Final report 2008.

[18] Bluyssen, P.M.: Towards an integrative approach of improving indoor air quality: Building and Environment 2009a; 44:1980-1989.

[19] WHO: Air quality guidelines, global update 2005: Particulate matter, ozone, nitrogen dioxide and sulphur dioxide. WHO Regional office for Europe; Denmark 2006: ISBN 9289021926.

[20] ASHRAE Standard 62.1-2004: Ventilation for acceptable indoor air quality. Atlanta; GA: American Society of Heating, Refrigerating and Air-Conditioning Engineers.

[21] CEN: EN 15251:2007: Criteria for the indoor environment including thermal, indoor air quality, light, and noise. Brussels, Belgium 2007.

[22] Bluyssen, P.M. and Adan O.C.G.: Marketing the indoor environment: standardization or performance on demand? Proceedings of Healthy buildings 2006, Lisboa; Portugal; Vol.5: 275280.

[23] Madigan, M., Martinko, J., Parker, J. (editors): Brock Biology of Microorganisms; 11th ed.; Prentice Hall 2005; New Jersey; USA: ISBN 0131443291.

[24] Billings, J.S., Mitchell, S.W., Bergey, D.H.: The composition of expired air and its effects upon animal life: Smithsonian Contributions to knowledge 1898, Washington, USA.

[25] Cain, W.S., Leaderer B.P., Isseroff, R., Berglund, L.G., Huey, R.J., Lipsitt, E.D. and Perlman, D.: Ventilation requirements in buildings: control of occupancy odor and tobacco smoke odor: Atmos. Environment 1983; 7(6): 1183-1197.

[26] Fanger, P.O. and Berg-Munch, B.: Ventilation requirements for the control of body odor. Proceedings of Engineering Foundation Conference on Management of Atmospheres in Tightly enclosed space; ASHRAE 1983; Atlanta; G.A.

[27] Boschi, N.: Education and training in indoor air sciences. NATO Science Series 1999; 2.

[28] Salares, V. and Ruest, K.: Canada's residential IAQ investigation training programme. Proceedings of Indoor Air 2008; Paper ID: 967; Copenhagen. 
[29] Maroni, M., Seifert, B., Lindvall, T.,: Indoor Air quality volume 3, Elsevier Science 1995: ISBN 9780080534626.

[30] Spengler, J.D., Samet, J.M., McCarthy, J.F. (eds): Indoor air quality handbook. McGrawhill, USA, 2005: ISBN 0-07-445549-4.

[31] Bluyssen, P.M.: The Indoor Environment Handbook, How to make buildings healthy and comfortable. Earthscan 2009b, London, UK: ISBN 9781844077878.

[32] Le Grenelle Environnement: Summary report on Round Table discussions held at the Hôtel de Roquelaure on 24, 25 and 26 October 2007.http://www.legrenelle-environnement.fr/grenelleenvironnement/IMG/pdf/rounded_table.pdf, 32 pages.

[33] PNSE: Propositions pour un deuxième Plan National Santé Environnement 2009-2013: Presented to the Minister Council in June 2009. Adopted and published in July 2009.

[34] Vereniging Eigen huis: Eigen huis en onderhoud. Amersfoort 2007, The Netherlands: ISBN 9789052411705.

[35] FEA: A healthier home - but how?: Federal Environment Agency 2005.

[36] Crump, D.: Maintaining good air quality in your home. BRE IP 9/04, CRC Ltd, London 2004.

[37] Yu, C. and Crump, D.: Indoor Air Quality Criteria for Homes for Assessing "Health and Wellbeing". In Advances in Eco-materials: Proceedings of the Eighth International Conference on Eco-materials (ICEM8 2007), 9-11 July 2007; London UK. Vol. 2: 337-344.

[38] Crump, D., Dengel, A. and Swainson, M.: Indoor air quality in highly energy efficient homes - a review. NHBC Foundation report NF19, IHS BRE Press 2009.

[39] Saarela, K. and Tirkonen T.: M1, Emission Classification of Building Materials: Protocol for Chemical and Sensory Testing of Building Materials. The Building Information Foundation RS; Finland 2004: ISBN 951-682-755-1 version 15.

[40] ISO/TS21929: Building construction - sustainability in building construction - sustainability indicators - Part I Framework for the development for indicators for buildings. International Organization for Standardization, Geneva, Switzerland 2006.

[41] ISO/TS 21931-1: Sustainability in building construction - Framework for methods of assessment for environmental performance of construction works - Part 1: Buildings, Revision of ISO/TS 21931-1: 2006, International Organization for Standardization, Geneva, Switzerland, 2008.

[42] CEN, prEN 15643-1 and 2: Sustainability of construction works - Sustainability assessment of buildings - Part 1: General framework, and Part 2: Framework for the assessment of environmental performance, AFNOR, France 2008.

[43] Bluyssen, P.M.: Towards new methods and ways to create healthy and comfortable buildings: Building and Environment 2010; 45: 808-818.

[44] Jenkins, P., McEwen, D.P., Martens, J.R.: Olfactory cilia: liking cilia function and human disease: Chem. Senses 2009; 34: 451-464. 